\title{
Bourse de voyage pour le Congrès de l'Acsp
}

Acsp-Assemblée générale annuelle, Bishop's University / Université de Sherbrooke, Lennoxville / Sherbrooke, Québec, 6-8 juin 1999

L'Association canadienne de science politique reçoit une subvention du Conseil de recherches en sciences humaines du Canada pour aider les membres des régions éloignées à assister au congrès. Ces fonds, qui sont surtout destinés aux membres les moins établis, seront répartis d'ici le 31 janvier 1999; ils seront alloués sur une base proportionnelle aux personnes qui en font la demande et qui remplissent les cinq critères suivants :

(1) Elles doivent avoir été membres de l'Association canadienne de science politique depuis les deux dernières années précédant la demande de bourse.

(2) Elles doivent présenter une communication lors du congrès (une bourse par communication).

(3) Elles doivent: (a) être membres non permanents d'un corps professoral; ou (b) être inscrits au moins en troisième année d'un programme de doctorat; ou (c) avoir reçu leur doctorat au cours des cinq dernières années et ne pas occuper en ce moment un poste à temps plein.

(4) Les bourses de voyage seront accordées aux personnes qui n'en ont pas reçu une l'année prédédente.

(5) Une bourse de voyage peut seulement être consentie aux personnes qui enseignent (dans le cas de 3[a]) ou qui étudient ou résident (dans le cas de 3[b]) ou qui résident (dans le cas de 3[c]) à plus de 500 $\mathrm{km}$ du lieu où se déroulera le congrès.

Prière d'adresser toute demande de bourse de voyage au secrétaire-trésorier, Association canadienne de science politique, bureau 204, 260, rue Dalhousie, Ottawa (Ontario) K1N 7E4, d'ici le 15 janvier 1999. Les formulaires de demande sont disponibles au secrétariat de l'Association (téléphone : 613-562-1202; télécopieur : 613-241-0019; courrier électronique : cpsa@csse.ca). 